\title{
Therapeutic effects of triptolide via the inhibition of IL-1ß expression in a mouse model of ulcerative colitis
}

\author{
HAIFENG ZHANG ${ }^{1}$, CHEN GONG $^{2}$, LISHUAI QU ${ }^{3}$, XIAOLING DING $^{3}$, WEI CAO ${ }^{3}$, \\ HAIQIN CHEN $^{3}$, BIN ZHANG ${ }^{1}$ and GUOXIONG ZHOU ${ }^{3}$ \\ ${ }^{1}$ Department of Infectious Diseases, The Affiliated Hospital of Nantong University, Nantong, Jiangsu 226001; \\ ${ }^{2}$ Department of Gastroenterology, The First People's Hospital of Taicang, Taicang, Jiangsu 215401; \\ ${ }^{3}$ Department of Gastroenterology, The Affiliated Hospital of Nantong University, Nantong, Jiangsu 226001, P.R. China
}

Received March 13, 2015; Accepted March 29, 2016

DOI: $10.3892 / \mathrm{etm} .2016 .3490$

\begin{abstract}
The present study aimed to investigate the effect of triptolide (TL) on ulcerative colitis (UC) and explore the potential association between the therapeutic effects of TL and IL- $1 \beta$ expression using a 4,4-dimethyl-4-silapentane-1-sulfonic acid (DSS)-induced mouse model to simulate human UC. A total of $70 \mathrm{BALB} / \mathrm{c}$ female mice were randomly allocated into seven equal groups: Group A, blank control; group B, normal saline injection; group C, propylene glycol injection; group D (TL1), $0.2 \mathrm{mg} / \mathrm{kg} \mathrm{TL}$; group E (TL2), $0.4 \mathrm{mg} / \mathrm{kg} \mathrm{TL}$; group F (TL3), $0.6 \mathrm{mg} / \mathrm{kg} \mathrm{TL}$; and group $\mathrm{G}$, dexamethasone injection. Mice activity, diet and stool characteristics were recorded daily. Mice were sacrificed by cervical dislocation on day 8 , and disease activity indices, colon tissue histological scores and colonic histopathological scores were subsequently calculated. Serum levels of IL-1 $\beta$ were evaluated by enzyme-linked immunosorbent assay, and IL-1 $\beta$ expression levels were examined by reverse transcription-quantitative polymerase chain reaction with colonic mucosa specimen at the gene level and western blot analysis at the protein level. The IL-1 $\beta$ mRNA and protein expression levels were significantly elevated in the normal saline injection and propylene glycol injection groups compared with the blank control group and $(\mathrm{P}<0.01)$. In TL (TL2 and TL3)- and dexamethasone-treated mice, IL-1 $\beta$ expression levels were significantly decreased, as compared with the normal saline and propylene glycol injection groups $(\mathrm{P}<0.05)$. No significant difference was detected between TL
\end{abstract}

Correspondence to: Professor Guoxiong Zhou, Department of Gastroenterology, The Affiliated Hospital of Nantong University, 20 Xisi Road, Nantong, Jiangsu 226001, P.R. China

E-mail: zhouguoxiong@medmail.com.cn

Professor Bin Zhang, Department of Infectious Diseases, The Affiliated Hospital of Nantong University, Nantong, Jiangsu 226001, P.R. China

E-mail: binzane@163.com

Key words: interleukin-1 $\beta$, treatment, triptolide, ulcerative colitis
(TL2 and TL3) and dexamethasone treatments. The results of the present study indicated that IL-1 $\beta$ expression was upregulated in the UC mouse model, which may be associated with the development and progression of UC. Furthermore, TL inhibited IL-1 $\beta$ expression, suggesting that TL may be a novel therapeutic target for the treatment of UC.

\section{Introduction}

Triptolide (TL), which is a diterpenoid, is the main active component of the Tripterygium wilfordii plant. Previous studies have shown that TL has potent pharmacological activities, including anti-inflammation, anti-neoformative, immune regulation and microcirculation improvement (1-3). TL has been demonstrated to inhibit cancer cell proliferation in numerous types of cancer, increase the sensitivity of tumor cells to chemotherapy drugs and has also been used to treat various types of immune diseases (4-16). Interleukin (IL)- $1 \beta$ is a pro-inflammatory cytokine which is produced by mononuclear cells, mast cells, smooth muscle cells and endothelial cells, and is capable of activating various types of immune and inflammatory cells (17). There are two types of IL-1, IL-1 $\alpha$ and IL- $1 \beta$, and the bioactivities of IL-1 are predominantly mediated by IL-1 $\beta$ (17). Previous studies have indicated that patients with ulcerative colitis (UC) exhibit significantly increased serum levels of IL-1 $\beta$, as compared with healthy cohorts, and the expression levels of IL-1 $\beta$ in the affected colonic mucosa are also significantly increased, as compared with the non-affected mucosa (18-23). Conversely, the mRNA expression levels of IL-1 $\beta$ was not different between UC patients at non-active stage and healthy cohorts (24-26). In the present study, TL was used to treat a a 4,4-dimethyl-4-silapentane-1-sulfonic acid (DSS)-induced mouse model of UC mouse model to observe the association between alteration in IL-1 $\beta$ expression levels and UC severity. The present study aimed to validate the therapeutic effect of TL on UC by investigating its potential mechanism of inhibition of IL-1 $\beta$ expression.

\section{Materials and methods}

Mice. A total of 70 female BALB/c mice, aged 4-6 weeks and weighing 20-24 g were purchased from the Animal Care 
Facility of Yangzhou University (Yangzhou, China). Mice were maintained in cages at the Animal Care Facility of Nantong University (Nantong, China) for two weeks at $22-24^{\circ} \mathrm{C}$ and $49 \%$ humidity with a 12/12 h light/dark cycle. Mice were fed a mixed-feed formula and had ad libitum access to distilled drinking water. Drinking water and feed were fresh and changed daily. All animal experiments were approved by the Ethics Committee for Animal Care and Use of the Affiliated Hospital of Nantong University.

Establishment of the mouse model. Following acclimatization for two weeks, a DSS-induced (MP Biomedicals, Santa Ana, CA, USA) mouse model was established according to the method described by Stevceva et al (27). A total of 70 BALB/c female mice were randomly classified into seven equal groups and raised in separate cages (10 mice/cage). Group A received no treatment and was the blank control; group B, the DSS-induced model, received $0.2 \mathrm{ml}$ normal saline by intraperitoneal injection once a day; group $\mathrm{C}$ was intraperitoneally injected with $0.2 \mathrm{ml}$ propylene glycol (20\%) as a vehicle control once a day following successful DSS induction; groups D (TL1), E (TL2) and F (TL3) were intraperitoneally injected with TL (Zelang Medical Science and Technology Co., Ltd. Nanjing, China) dissolved in $20 \%$ propylene glycol at a daily dose of $0.2,0.4$ and $0.6 \mathrm{mg} / \mathrm{kg}$, respectively, following successful DSS induction; and group G was intraperitoneally injected with dexamethasone dissolved in normal saline at a daily dose of $0.1 \mathrm{mg} / \mathrm{kg}$.

Disease activity index (DAI). From the first day of DSS induction, the vigor, activity, diet, body weight change, stool characteristics and hematochezia condition of the mice were recorded each day. The DAI was calculated to analyze the effects of TL on UC, as follows: DAI score $=$ (body weight loss score + stool characteristics score + hematochezia score) / 3 (Table I) (28).

Gross morphology. Mice were sacrificed by cervical dislocation and the intestinal cavity was exposed via a longitudinal incision along the mesenteric junction. Following removal of the stools, the intestine was washed several times in pre-cooled normal saline, and dried using filter paper. The intestinal wall was spread and fixed with pins for visual inspection of inflammation and ulcer formation. Disease severity was evaluated according to the criteria outlined by Ekstrom (29), as shown in Table II. The intestinal segment with lesions was subsequently cut into three symmetrical sections ( $4 \mu \mathrm{m}$ each) using a microtome (CM1950; Leica Microsystems GmbH, Wetzlar, Germany). One section of the intestine was fixed in $4 \%$ formaldehyde for pathological analysis with hematoxylin and eosin (HE; Beyotime Institute of Biotechnology, Inc., Haimen, China) staining or paraffin-embedded for immunohistochemical staining; the second section was preserved at $-80^{\circ} \mathrm{C}$ for reverse transcription-quantitative polymerase chain reaction (RT-qPCR) analysis; and the third section was used for protein extraction and western blot analysis.

Histology. Following conventional paraffin embedding and segmentation using a microtome, tissue samples with prominent lesions were subjected to pathological analysis via HE staining in order to observe histological alterations. Using blinded analysis, the samples were graded according to the criteria outlined by Boirivant et al (30), as shown in Table III. Samples were independently graded by two pathologists, whom were blinded to the scoring of one another, and the mean of the two histology scores was calculated.

ELISA. ELISA was performed using an ELISA kit (Thermo Fisher Scientific, Inc., Waltham, MA, USA) according to the manufacturer's protocol. A standard linear regression curve was obtained by plotting a standard curve of the concentrations of the standard samples and the corresponding optical density (OD) values. The sample concentration was calculated according to the equation of the standard curve.

Immunohistochemistry. An immunohistochemical assay was performed according to the manufacturer's protocol (Abcam, Cambridge, MA, USA). IL-1 $\beta$-positive cells were stained a brown/yellow color, with the background appearing as light blue under the light microscope (Olympus Corporation, Tokyo, Japan). All sections were observed using an optical microscope under identical conditions. Cells with brown or brown/yellow granular particles in the nucleus or cytoplasm were considered as positive for IL-1 $\beta$ expression, whereas those without brown/yellow particles were considered to be IL-1 $\beta$-negative cells. At $x 400$ magnification, cells in $\geq 10$ visual fields were counted for each section and the percentage of positive cells was calculated. Cell staining intensity was graded in four tiers as follows: 0 , negative staining; 1 , weak positive staining; 2 , moderate positive staining; and 3 , strong positive staining. Five scales were used to grade the number of positive cells: 0 , no positive cells; $1,1-25 \%$ positive cells; $2,26-50 \%$ positive cells; $3,51-75 \%$ positive cells; and $4,76-100 \%$ positive cells.

RT-qPCR analysis. Total RNA from each mouse colon was extracted using TRIzol (Invitrogen; Thermo Fisher Scientific, Inc.). The extracted RNA was treated with DNAse I (Roche Diagnostics, Basel, Switzerland). Following measurement of concentration, the total RNA was stored at $-80^{\circ} \mathrm{C}$. Total RNA was reverse transcribed to cDNA using a SYBR Green Supermix kit (Tiangen Biotech (Beijing) Co., Ltd., Beijing, China). Forward and reverse primer sequences used to amplify IL- $1 \beta$ and $\beta$-actin were synthesized by the Sangon Biotech Co., Ltd. (Shanghai, China). The primers for IL-1 $\beta$ (607 bp) were as follows: Forward, 5'-AGCTGACCCTAA ACAGATGA3', and reverse, 5'-GATCTACACTCTCCAGCT GTAGC-3'. The primers for $\beta$-actin (446 bp) were as follows: Forward, 5'-GAGACC TTCAACACCCCAGC-3', and reverse, 5'-CCACAGGATTCCATACCCAA-3'. The mRNA expression levels of IL-1 $\beta$ were analyzed by RT-qPCR using the SYBR Green Supermix kit, according to the manufacturer's protocol. PCR was performed using a fluorescence quantitative PCR machine (Applied Biosystems; Thermo Fisher Scientific, Inc.), as follows: $95^{\circ} \mathrm{C}$ pre-degeneration for $2 \mathrm{~min}, 95^{\circ} \mathrm{C}$ degeneration for $15 \mathrm{sec}$, annealing at $58^{\circ} \mathrm{C}$ for $25 \mathrm{sec}$, and extension at $72^{\circ} \mathrm{C}$ for $35 \mathrm{sec}$ for 45 cycles. The fluorescent readout was obtained at $72^{\circ} \mathrm{C}$ during each cycle. In order to test the specificity of each reaction, melting curve analysis was performed, as follows: $95^{\circ} \mathrm{C}$ for $15 \mathrm{sec}, 60^{\circ} \mathrm{C}$ for $60 \mathrm{sec}$ and $95^{\circ} \mathrm{C}$ for $15 \mathrm{sec}$. The ratio of target gene to 
$\beta$-actin mRNA was used to evaluate the expression levels of the target gene. The mRNA expression levels of the target gene were normalized to those of $\beta$-actin using the $2^{-\Delta \Delta \mathrm{Cq}}$ method.

Western blotting. IL-1 $\beta$ protein expression was measured by western blot analysis. Total protein $(20 \mu \mathrm{l})$ was extracted from intestinal tissue samples and protein concentration was measured by UV spectrophotometry (Shanghai Mapada Instruments Co., Ltd., Shanghai, China). The protein was separated by sodium dodecyl sulfate-polyacrylamide gel electrophoresis and subsequently transferred onto a nitrocellulose membrane (GE Healthcare Bio-Sciences, Pittsburg, PA, USA). Following blocking for $4 \mathrm{~h}$ in $5 \%$ Tris-buffered saline with Tween-20 (TBST), the membrane was incubated with anti-mouse IL-1 $\beta$ primary antibody $(1: 2,500$; cat. no. ab200478; Abcam) at $4^{\circ} \mathrm{C}$ overnight. Subsequently, the membrane was washed five times in TBST for $10 \mathrm{~min}$ and incubated with secondary antibody (1:5,000; cat. no. A28175; Pierce Biotechnology; Thermo Fisher Scientific, Inc.) for $2 \mathrm{~h}$ at room temperature. Bands were visualized by enhanced chemiluminescence. Data were processed using ImageJ version 1.36b (National Institutes of Health, Bethesda, MA, USA), and the normalized expression level of IL-1 $\beta$ was measured as the gray scale ratio of IL-1 $\beta$ to $\beta$-actin bands.

Statistical analysis. Windows Excel 2010 software (Microsoft Corp., Redmond, WA, USA) was utilized to form a database of experimental results. SPSS 17.0 software (SPSS, Inc., Chicago, IL, USA) was used for statistical analysis. Numerical data was presented as the mean \pm standard deviation and analyzed by analysis of variance. $\mathrm{P}<0.05$ was considered to indicate a statistically significant difference.

\section{Results}

Association between DAI score and treatment with various doses of $T L$. Characteristics including vigor, body weight, activity, hair color, diet, stool property and hematochezia were assessed from the first day of DSS induction and DAI scores were calculated to assess the effect of TL on UC. Mice in the blank control group exhibited shiny hair, increased body weight, normal vigor and activity levels, and their diet and stool were normal. From the second or third day of receiving normal saline or propylene glycol injection, DSS-induced mice were anorexic, with decreased activity, piloerection, darkened hair color, weight loss and altered stool properties, including loose and soft stools. Hematochezia or occult fecal blood were observed on the fourth day following treatment, accompanies by prominent body weight loss and reduced activity. One mouse in the normal saline group succumbed to the treatment after six days. Mice in the TL2, TL3 and dexamethasone treatment groups exhibited improved diet and body weight, as compared with the normal saline or propylene glycol treatment groups. In addition, the vigor and activity of mice were improved, hair shine and color returned, stool properties returned to normal and hematochezia and occult fecal blood were alleviated (Fig. 1). In summary, The DAI scores of the normal saline injection and propylene glycol injection groups were significantly elevated as compared
Table I. Dextran sulfate sodium-induced ulcerative colitis scale.

\begin{tabular}{lclc}
\hline Score & $\begin{array}{c}\text { Body weight } \\
\text { loss }(\%)\end{array}$ & $\begin{array}{c}\text { Stool } \\
\text { characteristic }\end{array}$ & Hematochezia \\
\hline 0 & 0 & Normal & $(-)$ \\
1 & $1-5$ & In-between & \\
2 & $5-10$ & Loose & Occult blood (+) \\
3 & $10-15$ & In-between & \\
4 & $>15$ & Sparce & Gross blood $(++)$
\end{tabular}

Normal stool, shaped stools or in particles; loose stool, pasty or half-formed stool which is not adhesive to the anus; and sparce stool, watery stool which is adhesive to the anus. Occult blood was tested by the conventional benzidine method. (-), negative; $(+)$, positive; (++), strongly positive.

Table II. Gross morphology scoring.

\begin{tabular}{ll}
\hline Score & \multicolumn{1}{c}{ Description } \\
\hline 0 & No lesion \\
1 & Mucous hyperemia \\
2 & Ulcer area $<25 \%$ affected area \\
3 & Ulcer area $=25-50 \%$ affected area \\
4 & Ulcer area $>50 \%$ affected area \\
\hline
\end{tabular}

Table III. Histological scoring to evaluate the severity of intestinal inflammation.

\begin{tabular}{ll}
\hline Score & \multicolumn{1}{c}{ Description } \\
\hline 0 & Normal \\
1 & Extremely low white cell infiltration $(<10 \% \mathrm{hpf})$ \\
2 & Mild white cell infiltration $(10-25 \% \mathrm{hpf})$ \\
3 & Moderate white cell infiltration $(25-50 \% \mathrm{hpf})$ with \\
& increased vascular density and thickening of the \\
& intestine wall \\
& Massive white cell infiltration $(>50 \% \mathrm{hpf})$ with \\
& highly increased vascular density, intestinal crypt \\
& deformation and distortion, intestinal wall swelling \\
& and ulceration
\end{tabular}

Since mild infiltration of white blood cells into the mouse intestine mucosa was detected; histological score $>1$ was considered the baseline of inflammation. Disease activity index and gross scores were also taken into consideration. hpf, high power field.

with the blank control group $(\mathrm{P}<0.05)$; conversely, the scores for the TL and dexamethasone treatment groups were significantly decreased $(\mathrm{P}<0.05)$. The results suggest that treatment with TL and dexamethasone may alleviate the symptoms of mouse colon ulcerative colitis.

Gross morphology in each group. Mice in each group were scored according to the scale outlined in Table II. The results 


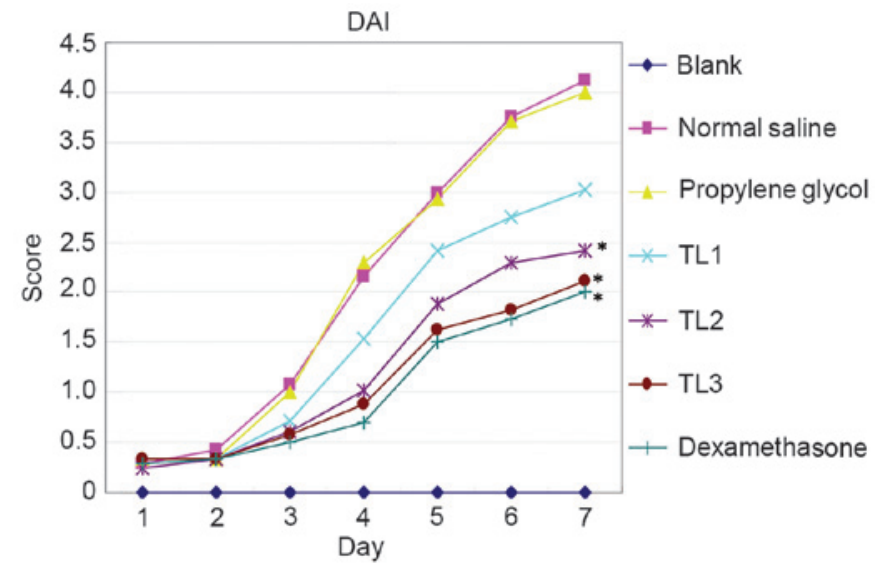

Figure 1. DAI scores among the groups from the first day of dosing. DAI, disease activity index; TL, triptolide. ${ }^{*} \mathrm{P}<0.05$, vs. the propylene glycol treatment and normal saline treatment groups.

are presented in Table IV. The gross morphology scores of the normal saline injection and propylene glycol injection groups were significantly elevated as compared with the blank control group $(\mathrm{P}<0.01)$, and the scores significantly decreased in the TL and dexamethasone treatment groups $(\mathrm{P}<0.01)$. No hyperemia, edema, erosion, or ulcer formations were detected in the colonic mucosa of mice in the blank control group. Three mice exhibited mild hyperemia of the colonic mucosa in the distal colon. Colonic lesions were found in the anus of mice in the normal saline and propylene glycol treatment groups, which were gradually aggravated resulting in moderate to severe mucosal hyperemia and edema, multiple sites of erosion and superficial ulceration. Mild hyperemia and edema were detected in the proximal colon. Conversely, mice that received TL or dexamethasone treatment demonstrated markedly reduced erosion and ulceration, and edema of the colonic mucosa was mild or moderate. Hyperemia and edema in the proximal colon were not obvious. The results suggest that treatment with TL and dexamethasone may reduce gross morphology and scoring.

Histological scoring by HE staining. Mice in each group were scored according to the scale outlined in Table III. HE staining demonstrated good colonic mucosa integrity in mice of the blank control group, with well-arranged lamina propria glands of normal morphology. Conversely, colonic mucosal lesion, loss, erosion and ulceration were detected in mice in the normal saline and propylene glycol treatment groups, with extensive lymphocyte and mononuclear cell infiltration and minimal neutrophil infiltration into the mucosa and submucosa. Lymphoid follicles were occasionally formed, accompanied by lamina propria gland deformation and disordered arrangement. The severity of inflammatory cell infiltration, ulceration, and erosion was milder in mice that received TL or dexamethasone treatment, as compared with the normal saline or propylene glycol treatment groups (Table V). The histological scores of the normal saline injection and propylene glycol injection groups were significantly elevated as compared with the blank control group $(\mathrm{P}<0.01)$. The scores significantly decreased in the TL and dexamethasone treatment groups $(\mathrm{P}<0.01)$. The results
Table IV. Gross morphology score comparison among groups.

\begin{tabular}{lc}
\hline Group $(\mathrm{n}=8)$ & Gross score \\
\hline Blank control & $0.20 \pm 0.08^{\mathrm{a}}$ \\
Normal saline treatment & $3.10 \pm 0.32$ \\
Propylene glycol & $3.02 \pm 0.28$ \\
TL1 $(0.2 \mathrm{mg} / \mathrm{kg})$ & $2.86 \pm 0.24$ \\
TL2 $(0.4 \mathrm{mg} / \mathrm{kg})$ & $2.24 \pm 0.20^{\mathrm{a}}$ \\
TL3 $(0.6 \mathrm{mg} / \mathrm{kg})$ & $2.06 \pm 0.20^{\mathrm{a}}$ \\
Dexamethasone & $1.82 \pm 0.16^{\mathrm{a}}$ \\
\hline
\end{tabular}

Mice were scored according to the scale outlined in Table II. Data are presented as the mean \pm standard deviation. ${ }^{\mathrm{a}} \mathrm{P}<0.01$, vs. propylene glycrol treatment and normal saline treatment. TL, triptolide.

suggest that treatment with TL and dexamethasone may reduce ulceration and erosion.

Serum IL-1 $\beta$ levels in the various groups. Serum levels of IL-1 $\beta$ in the blank control, normal saline and propylene glycol treatment groups were $42.44 \pm 8.26,96.39 \pm 10.10$ and $89.53 \pm 9.88 \mathrm{pg} / \mathrm{ml}$, respectively. Serum IL-1 $\beta$ levels were significantly increased in mice in the normal saline and propylene glycol treatment groups, as compared with those in the blank control group $(\mathrm{P}<0.01)$. Serum IL-1 $\beta$ levels were 69.69 \pm 7.36 , $61.75 \pm 7.10$ and $59.26 \pm 6.22 \mathrm{pg} / \mathrm{ml}$ for mice in the TL2, TL3 and dexamethasone treatment groups, respectively, which was significantly decreased, as compared with the normal saline and propylene glycol treatment groups $(\mathrm{P}<0.01)$. However, the serum level of IL-1 $\beta$ was $84.23 \pm 8.52 \mathrm{pg} / \mathrm{ml}$ in mice that received TL1 treatment, which was not significantly different from the normal saline and propylene glycol treatment groups. No significant differences in serum IL-1 $\beta$ levels were detected between the TL2, TL3 and dexamethasone treatment groups. The results suggest that treatment with TL and dexamethasone may decrease the serum levels of IL-1 $\beta$.

Immunohistological scores in the various groups. Fig. 2 shows the immunohistological images and Table VI outlines the comparison of immunohistological scores among the groups. As compared with the weak expression of IL-1 $\beta$ detected in the colonic mucosa of mice in the blank control group, IL-1 $\beta$ expression levels were significantly increased the normal saline and propylene glycol groups $(\mathrm{P}<0.01)$. Furthermore, IL-1 $\beta$ expression levels were significantly decreased in the TL2, TL3 and dexamethasone treatment groups, as compared with the normal saline and propylene glycol groups $(\mathrm{P}<0.01)$. No significant differences were detected among the TL2, TL3 and dexamethasone treatment group. The results suggest that treatment with TL and dexamethasone may downregulate the expression of IL-1 $\beta$ in colon tissue.

$I L-1 \beta$ mRNA expression levels in the various groups. As compared with the weak IL-1 $\beta$ mRNA expression detected in the colonic mucosal tissue of mice in the blank control group, IL-1 $\beta$ mRNA expression was significantly increased in the normal saline and propylene glycol treatment groups $(\mathrm{P}<0.01)$. 
Furthermore, as compared with the blank control group, IL-1 $\beta$ mRNA expression levels were markedly increased in the TL2, TL3 and dexamethasone treatment groups, and were significantly reduced, as compared with the normal saline and propylene glycol treatment groups $(\mathrm{P}<0.01)$. No significant differences were detected among the TL2, TL3 and dexamethasone treatment groups (Fig. 3). These results suggest that treatment with TL and dexamethasone may inhibit IL-1 $\beta$ mRNA expression in colon tissue.

$I L-1 \beta$ protein expression levels in the various groups. IL-1 $\beta$ protein expression was detected by western blot analysis. Fig. 4 shows the western blot images of IL-1 $\beta$ and $\beta$-actin in each group. As compared with the weak IL-1 $\beta$ protein expression levels detected in the colonic mucosa tissue of mice in the blank control group, IL-1 $\beta$ protein expression levels were significantly upregulated in the normal saline and propylene glycol treatment groups $(\mathrm{P}<0.01)$. Furthermore, as compared with the blank control group, IL-1 $\beta$ protein expression levels were markedly increased in the TL2, TL3 and dexamethasone treatment groups, and were significantly decreased, as compared with the normal saline and propylene glycol treatment groups $(\mathrm{P}<0.01)$. No significant differences were detected among the TL2, TL3 and dexamethasone treatment groups. The results suggest that treatment with TL and dexamethasone may suppress IL-1 $\beta$ expression in colon tissue.

\section{Discussion}

To date, the immune regulation mechanism of TL remains unclear; this is partially due to the broad therapeutic profile of TL on various diseases and the complexity of the immune system (2). Previous studies have indicated that inhibition of $\mathrm{T}$ cell proliferation, induction of $\mathrm{T}$ cell apoptosis, suppression of nuclear factor (NF)- $\mathrm{kB}$ activity, repression of tumor angiogenesis, anti-oxidation and anti-lipid peroxidation may be associated with the therapeutic mechanism of TL $(3-16,31)$.

$\mathrm{Li}$ et al (32) have previously investigated the mechanism of TL attenuation of Crohn's colitis in 10-12 week old IL-10 gene-deficient (IL-10(-)/(-)) mice with established colitis. Following chronic TL administration, their results indicated that TL therapy may restore the homeostatic balance of lamina propria $\mathrm{T}$ cell apoptosis within the gut, and demonstrated a novel mechanism of action for TL therapy, which was mediated via regulation of the IL-6/signal transducer and activator of transcription (STAT3)/suppressor of cytokine signalling 3 signaling pathway. Another study (33) has demonstrated that TL attenuated experimental colitis by repressing IL-17 expression via the downregulation of the IL-6/STAT3 signaling pathway. Furthermore, histological examination demonstrated that TL significantly reduced the severity of colitis in a IL-10-deficient $\mathrm{C} 3 \mathrm{H} / \mathrm{HeJBir}$ mice. Therefore, TL administration suppressed the IL-6/STAT3 signaling pathway and repressed IL-17 gene expression in vivo. In addition, treatment with $20 \mathrm{ng} / \mathrm{ml} \mathrm{TL}$ in vitro was capable of downregulating the IL-6/STAT3 pathway and reducing IL-17 expression levels in cultured colonic explants from patients with Crohn's disease (33).

In a previous study, Yu et al (34) demonstrated that TL administration successfully ameliorated experimental colitis
Table V. Histology score comparison among groups.

\begin{tabular}{lc}
\hline Group $(\mathrm{n}=8)$ & Histology score \\
\hline Blank control & $0.75 \pm 0.10^{\mathrm{a}}$ \\
Normal saline treatment & $3.56 \pm 0.32$ \\
Propylene glycol & $3.48 \pm 0.30$ \\
TL1 $(0.2 \mathrm{mg} / \mathrm{kg})$ & $2.80 \pm 0.28$ \\
TL2 $(0.4 \mathrm{mg} / \mathrm{kg})$ & $2.02 \pm 0.22^{\mathrm{a}}$ \\
TL3 $(0.6 \mathrm{mg} / \mathrm{kg})$ & $1.86 \pm 0.20^{\mathrm{a}}$ \\
Dexamethasone & $1.66 \pm 0.19^{\mathrm{a}}$
\end{tabular}

Mice were scored according to the scale outlined in Table III. Data are presented as the mean \pm standard deviation. ${ }^{\mathrm{a}} \mathrm{P}<0.01$, vs. propylene glycrol treatment and normal saline treatment. TL, triptolide.

Table VI. Immunohistological score comparison among groups.

\begin{tabular}{lc}
\hline Group $(\mathrm{n}=7)$ & Immunohistological \\
\hline Blank control & $1.00 \pm 0.00^{\mathrm{a}}$ \\
Normal saline treatment & $3.46 \pm 0.36$ \\
Propylene glycol & $3.38 \pm 0.38$ \\
TL1 $(0.2 \mathrm{mg} / \mathrm{kg})$ & $2.88 \pm 0.26$ \\
TL2 $(0.4 \mathrm{mg} / \mathrm{kg})$ & $2.22 \pm 0.23^{\mathrm{a}}$ \\
TL3 $(0.6 \mathrm{mg} / \mathrm{kg})$ & $2.10 \pm 0.19^{\mathrm{a}}$ \\
Dexamethasone & $1.88 \pm 0.23^{\mathrm{a}}$
\end{tabular}

Data are presented as the mean \pm standard deviation. TL, triptolide. ${ }^{\text {a }}<0.01$, vs. the propylene glycol and normal saline treatment groups.

by inhibiting the toll-like receptor (TLR)/NF- $\mathrm{KB}$ signaling pathway. TLR2 and TLR4 were upregulated in IL-10(-)/(-) mice, suggesting that TL inhibited the TLRs/NF- $\kappa B$ signaling pathway in vivo. In addition, in vitro administration of TL was able to downregulate the TLRs/NF- $\mathrm{BB}$ pathway in cultured colonic explants from patients with Crohn's disease. These results suggested that TL may have a therapeutic effect in experimental colitis and indicated TL as a potential therapeutic agent for the treatment of Crohn's disease. Wei et al (35) have previously demonstrated that TL administration for 8 weeks results in a significant decrease in the severity of colitis, which was accompanied by reduced expression of TNF- $\alpha$, IFN- $\gamma$ and IL-4 in the colon. Serum amyloid A levels were decreased in TL-treated mice and IL-12 and IL-23 gene expression levels in the colon were also downregulated following treatment. Furthermore, TL administration markedly reduced NF- $\mathrm{KB}$ activation in the colonic mucosa of IL-10(-)/(-) mice. These results suggested that the efficacy of TL treatment for the reduction of intestinal inflammation in IL-10(-)/(-) mice may be a result of anti-inflammatory and immunosuppressive activity.

TL showed significant protective effect on rat colitis induced by trinitrobenzene sulfonic acid, and both lowand high-dose TL significantly alleviated the colon lesion and improved the histological score by reducing mRNA 


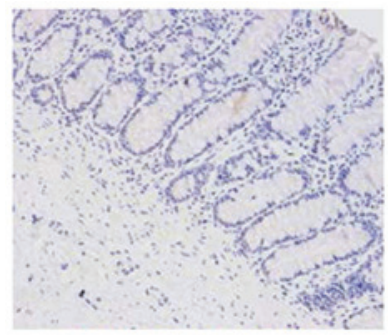

Blank control

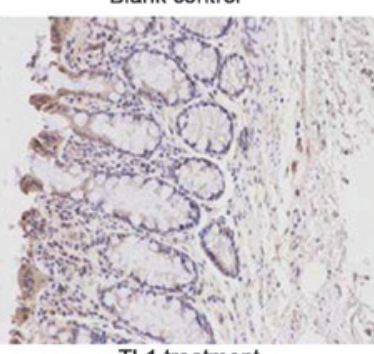

TL1 treatment

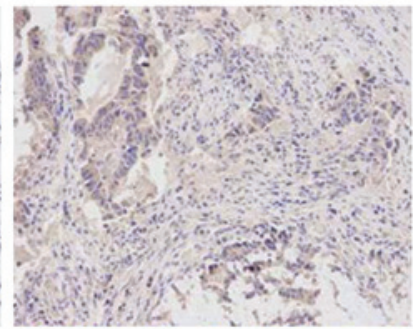

Normal saline treatment

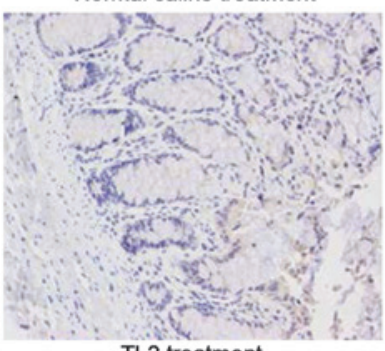

TL2 treatment

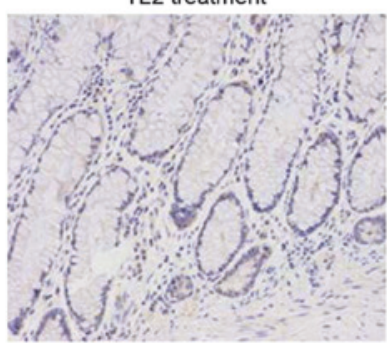

Dexamethasone treatment

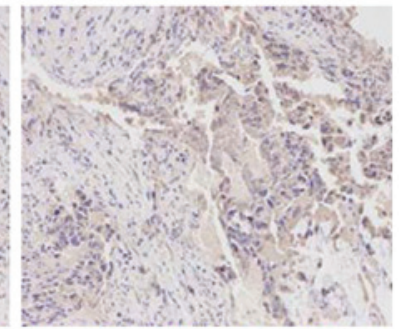

Propylene glycrol treatment
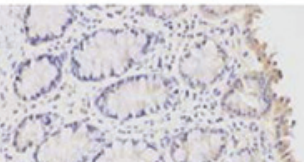

if
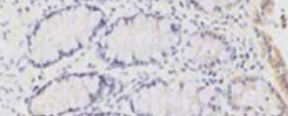

TL3 treatment

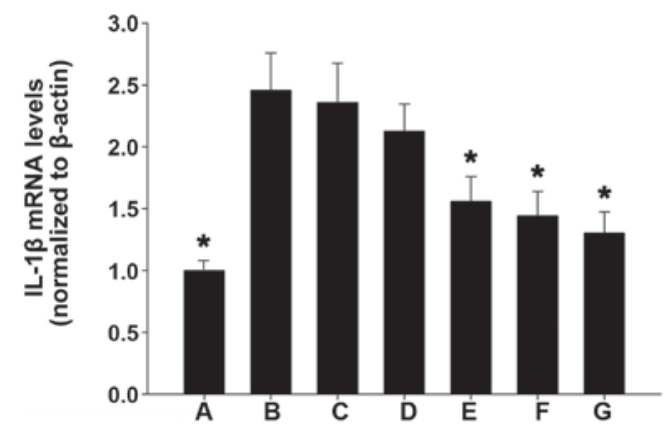

Figure 3. Reverse transcription-quantitative polymerase chain reaction analysis of IL-1 $\beta$ mRNA expression levels in the various groups. (A) Blank control; (B) normal saline; (C) propylene glycol; (D) $0.2 \mathrm{mg} / \mathrm{kg}$ triptolide; (E) $0.4 \mathrm{mg} / \mathrm{kg}$ triptolide; (F) $0.6 \mathrm{mg} / \mathrm{kg}$ triptolide; and (G) dexamethasone treatment groups. The data are presented as the mean \pm standard deviation. ${ }^{*} \mathrm{P}<0.01$, vs. the propylene glycrol and normal saline treatment groups. IL, interleukin.

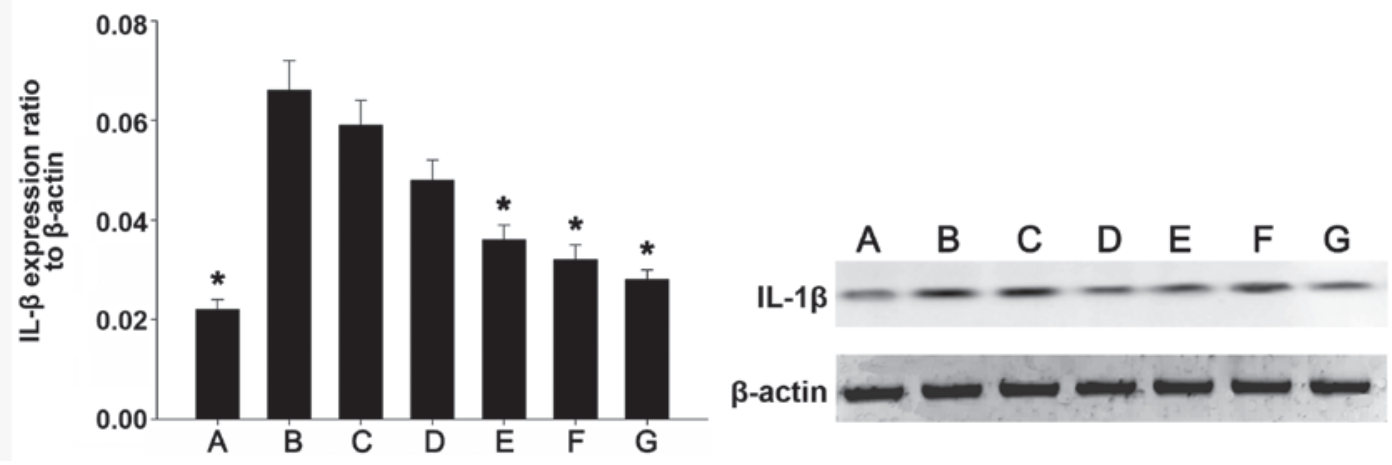

Figure 4. The expression levels of IL-1 $\beta$ and $\beta$-actin in the intestine of the mice from each group. (A) Blank control; (B) normal saline; (C) propylene glycol; (D) $0.2 \mathrm{mg} / \mathrm{kg}$ triptolide; (E) $0.4 \mathrm{mg} / \mathrm{kg}$ triptolide; (F) $0.6 \mathrm{mg} / \mathrm{kg}$ triptolide; and (G) dexamethasone treatment groups. The ratio of IL-1 $\beta$ protein to $\beta$-actin as determined by densitometry is shown. The data are presented as the mean \pm standard deviation. $\mathrm{P}<0.01$, vs. the expression levels in the propylene glycol and normal saline treatment groups. IL, interleukin. 
expression of NF- $\kappa \mathrm{B}$ p65, IL-1 $\beta$, and TNF- $\alpha$ (36). By comparing the effect of TL and dexamethasone on a mouse model of DSS-induced ulcerative colitis, the authors of the present study have previously indicated that TL may alleviate the symptoms of UC in the colons of mice by downregulating the expression of secondary lymphoid tissue chemokine, implying that TL may execute its therapeutic effect on UC by inhibiting the overexpression of secondary lymphoid tissue chemokine (37).

The results of the present study demonstrated that, following treatment with TL, the syndromes of mouse colon ulcerative colitis were significantly alleviated, as indicated by significantly reduced body weight loss, DAI and gross morphology observation and scoring. Histological observation and scores were also improved in the TL2, TL3 and dexamethasone treatment groups, as compared with normal saline or propylene glycol treatment, which was consistent with the reduced ulceration and erosion, significantly decreased serum levels of IL-1 $\beta$ and the downregulated expression of IL-1 $\beta$ in colon tissue. IL-1 $\beta$ expression levels were upregulated in mice that received TL treatment, as compared with blank control mice, which may be due to the DSS induction of all TL-treated mice. The present findings also indicated that TL2 and TL3, and dexamethasone treatment had a similar therapeutic effect, which may be associated with the inhibition of IL- $1 \beta$ overexpression; suggesting that TL treatment may be a therapeutic option for the treatment of UC.

Although the results of the present study suggested that TL induced a therapeutic effect on ulcerative colitis through the inhibition of IL-1 $\beta$, it remains unclear whether TL is similar to dexamethasone in its ability to inhibit multiple types of cytokines. Future studies should focus on whether TL has a therapeutic effect on UC that are non-responsive to hormone or mesalazine-like medicines by inhibiting the expression of multiple types of cytokines, which may offer an alternative treatment option for patients with UC.

In conclusion, the present study demonstrated the therapeutic effect of TL on UC, which may be associated with the inhibition of IL-1 $\beta$ expression. These results suggested that TL may be a novel therapeutic target for the treatment of UC, although further studies are required in order to elucidate the underlying mechanism.

\section{Acknowledgements}

The present study was supported by the Social Application Research Plans Foundation of Nantong (grant no. 2012074).

\section{References}

1. Zheng Y, Zhang WJ and Wang XM: Triptolide with potential medicinal value for diseases of the central nervous system. CNS Neurosci Ther 19: 76-82, 2013.

2. Liu Q: Triptolide and its expanding multiple pharmacological functions. Int Immunopharmacol 11: 377-383, 2011.

3. Kusunoki N, Yamazaki R, Kitasato H, Beppu M, Aoki H and Kawai S: Triptolide, an active compound identified in a traditional Chinese herb, induces apoptosis of rheumatoid synovial fibroblasts. BMC Pharmacol 4: 2-11, 2004.

4. Zhou GX, Ding XL, Huang JF, Zhang H, Wu SB, Cheng JP and Wei Q: Apoptosis of human pancreatic cancer cells induced by Triptolide. World J Gastroenterol 14: 1504-1509, 2008.
5. Krakauer T, Chen X, Howard OM and Young HA: Triptolide attenuates endotoxin- and staphylococcal exotoxin-induced T-cell proliferation and production of cytokines and chemokines. Immunopharmacol Immunotoxicol 27: 53-66, 2005.

6. Liu Q, Chen T, Chen G, Li N, Wang J, Ma P and Cao X: Immunosuppressant triptolide inhibits dendritic cell-mediated chemoattraction of neutrophils and T cells through inhibiting Stat3 phosphorylation and NF-kappaB activation. Biochem Biophys Res Commun 345: 1122-1130, 2006.

7. Shao H, Ma J, Guo T and Hu R: Triptolide induces apoptosis of breast cancer cells via a mechanism associated with the Wnt/ $\beta$-catenin signaling pathway. Exp Ther Med 8: 505-508, 2014.

8. Wang CY, Bai XY and Wang CH: Traditional Chinese medicine: A treasured natural resource of anticancer drug research and development. Am J Chin Med 42: 543-559, 2014.

9. Wang X, Zhang L, Duan W, Liu B, Gong P, Ding Y and Wu X: Anti-inflammatory effects of triptolide by inhibiting the NF- $\mathrm{KB}$ signalling pathway in LPS-induced acute lung injury in a murine model. Mol Med Rep 10: 447-452, 2014.

10. Kwon HY, Kim KS, An HK, Moon HI, Kim HJ and Lee YC: Triptolide induces apoptosis through extrinsic and intrinsic pathways in human osteosarcoma U2OS cells. Indian J Biochem Biophys 50: 485-491, 2013

11. Ding X, Zhang B, Pei Q, Pan J, Huang S, Yang Y, Zhu Z, Lv Y and Zou X: Triptolide induces apoptotic cell death of human cholangiocarcinoma cells through inhibition of myeloid cell leukemia-1. BMC Cancer 14: 271, 2014.

12. Liu Y, Xiao E, Yuan L and Li G: Triptolide synergistically enhances antitumor activity of oxaliplatin in colon carcinoma in vitro and in vivo. DNA Cell Biol 33: 418-425, 2014.

13. Wei D and Huang Z: Anti-inflammatory effects of triptolide in LPS-induced acute lung injury in mice. Inflammation 37: 1307-1316, $2014 \mathrm{~g}$.

14. Mujumdar N, Banerjee S, Chen Z, Sangwan V, Chugh R, Dudeja V, Yamamoto M, Vickers SM and Saluja AK: Triptolide activates unfolded protein response leading to chronic ER stress in pancreatic cancer cells. Am J Physiol Gastrointest Liver Physiol 306: G1011-G1020, 2014.

15. Li J, Liu R, Yang Y, Huang Y, Li X, Liu R and Shen $X$ : Triptolide-induced in vitro and in vivo cytotoxicity in human breast cancer stem cells and primary breast cancer cells. Oncol Rep 31: 2181-2186, 2014.

16. Chen Z, Sangwan V, Banerjee S, Chugh R, Dudeja V, Vickers SM and Saluja AK. Triptolide sensitizes pancreatic cancer cells to TRAIL-induced activation of the death receptor pathway. Cancer Lett 348: 156-166, 2014

17. Zhao R, Zhou H and Su SB: A critical role for interleukin-1 $\beta$ in the progression of autoimmune diseases. Int Immunopharmacol 17: 658-669, 2013.

18. Li Z, Zhang de K, Yi WQ, Ouyang Q, Chen YQ and Gan HT: NF-kappaB p65 antisense oligonucleotides may serve as a novel molecular approach for the treatment of patients with ulcerative colitis. Arch Med Res 39: 729-734, 2008.

19. Dharmani P and Chadee K: Biologic therapies against inflammatory bowel disease: A dysregulated immune system and the cross talk with gastrointestinal mucosa hold the key. Curr Mol Pharmacol 1:195-212, 2008

20. Leal RF, Coy CS, Ayrizono ML, Fagundes JJ, Milanski M, Saad MJ, Velloso LA and Góes JR: Differential expression of pro-inflammatory cytokines and a pro-apoptotic protein in pelvic ileal pouches for ulcerative colitis and familial adenomatous polyposis. Tech Coloproctol 12: 33-38, 2008.

21. Chang YY and Ouyang Q: Expression and significance of mucosal beta-defensin-2, TNFalpha and IL-1beta in ulcerative colitis. Zhonghua Neike Zazhi 47: 11-14, 2008 (In Chinese).

22. Yamamoto T, Maruyama Y, Umegae S, Matsumoto K and Saniabadi AR: Mucosal inflammation in the terminal ileum of ulcerative colitis patients: Endoscopic findings and cytokine profiles. Dig Liver Dis 40: 253-259, 2008.

23. Szkaradkiewicz A, Marciniak R, Chudzicka-Strugała I, Wasilewska A, Drews M, Majewski P, Karpiński T and Zwoździak B: Proinflammatory cytokines and IL-10 in inflammatory bowel disease and colorectal cancer patients. Arch Immunol Ther Exp (Warsz) 57: 291-294, 2009.

24. Førland DT, Johnson E, Saetre L, Lyberg T, Lygren I and Hetland G: Effect of an extract based on the medicinal mushroom Agaricus blazei Murill on expression of cytokines and calprotectin in patients with ulcerative colitis and Crohn's disease. Scand J Immunol 73: 66-75, 2011. 
25. D'Incà R, Barollo M, Scarpa M, Grillo AR, Brun P, Vettorato MG Castagliuolo I and Sturniolo GC: Rectal administration of Lactobacillus casei DG modifies flora composition and Toll-like receptor expression in colonic mucosa of patients with mild ulcerative colitis. Dig Dis Sci 56: 1178-1187, 2011.

26. Zimmerman NP, Vongsa RA, Wendt MK and Dwinell MB: Chemokines and chemokine receptors in mucosal homeostasis at the intestinal epithelial barrier in inflammatory bowel disease. Inflamm Bowel Dis 14: 1000-1011, 2008.

27. Stevceva L, Pavli P, Husband AJ and Doe WF: The inflammatory infiltrate in the acute stage of the dextran sulphate sodium induced colitis: B cell response differs depending on the percentage of DSS used to induce it. BMC Clin Pathol 1: 3, 2001.

28. Murano M, Maemura K, Hirata I, Toshina K, Nishikawa T, Hamamoto N, Sasaki S, Saitoh O and Katsu K: Therapeutic effect of intracolonically administered nuclear factor kappa B (p65) antisense oligonucleotide on mouse dextran sulphate sodium (DSS)-induced colitis. Clin Exp Immunol 120: 51-58, 2000.

29. Ekström GM: Oxazolone-induced colitis in rats: Effects of budesonide, cyclosporin A, and 5-aminosalicylic acid. Scand J Gastroenterol 33: 174-179, 1998.

30. Boirivant M, Fuss IJ, Ferroni L, De Pascale M and Strober W: Oral administration of recombinant cholera toxin subunit B inhibits IL-12-mediated murine experimental (trinitrobenzene sulfonic acid) colitis. J Immunol 166: 3522-3532, 2001.
31. Liu MX, Dong J, Yang YJ, Yang XL and Xu HB: Progress in research on triptolide. Zhongguo Zhong Yao Za Zhi 30: 170-174, 2005 (In Chinese)

32. Li Y, Tian Y, Zhu W, Gong J, Zhang W, Yu C, Gu L, Li N and Li J: Triptolide induces suppressor of cytokine signaling-3 expression and promotes lamina propria mononuclear cells apoptosis in Crohn's colitis. Int Immunopharmacol 16: 268-274, 2013.

33. Li Y, Yu C, Zhu WM, Xie Y, Qi X, Li N and Li JS: Triptolide ameliorates IL-10-deficient mice colitis by mechanisms involving suppression of IL-6/STAT3 signaling pathway and down-regulation of IL-17. Mol Immunol 47: 2467-2474, 2010.

34. Yu C, Shan T, Feng A,Li Y,Zhu W, Xie Y,Li N and Li J: Triptolide ameliorates Crohn's colitis is associated with inhibition of TLRs/NF- $\kappa B$ signaling pathway. Fitoterapia 82: 709-715, 2011.

35. Wei X, Gong J, Zhu J, Niu L, Zhu W, Li N and Li J: Therapeutic effects of triptolide on interleukin-10 gene-deficient mice with colitis. Int Immunopharmacol 8: 1808-1812, 2008.

36. Zhou J, Wu S,Chen X and Peng Y: Protective effects of tripterine on rat colitis by trinitrobenzene sulfonic acid. Wei Chang Bing Xue 12: 144-147, 2007 (In Chinese).

37. Zhang H, Zhang X, Ding X, Cao W, Qu L and Zhou G: Effect of secondary lymphoid tissue chemokine suppression on experimental ulcerative colitis in mice. Genet Mol Res 13: 3337-3345, 2014 